\title{
A Systematization of the Concept of Transmedia: Update, Reinterpretation and Redefinition of the Concept
}

\section{Hyuk Daniel Byun ${ }^{1}$ and Young-Sung Kwon ${ }^{2, *}$}

Department of Film, Television, and Multimedia, Sungkyunkwan University, Seoul, South Korea

Department of Journalism and Mass Communication, Sungkyunkwan University, Jongno-gu, Seoul, KR 110-745 South Korea

\begin{abstract}
The main purpose of this research study was to improve the concept of transmedia by adjusting, updating and redefining it in the form of a verb, which was different from its current definition as a noun. This study sought to achieve a number of objectives. In achieving the objectives, the study sought to use a historical analysis technique. The objectives of this study were to: 1) provide a new interpretation of transmedia; 2) to suggest an adjustment and a new definition of transmedia as a verb; 3 ) to provide a critical analysis of Jenkins' conception of transmedia storytelling. The study has revealed that Jenkins' conception of transmedia storytelling has been vague. The study has also pointed out the weaknesses of Jenkins' ideas on transmedia storytelling, which have been used to show that the suggestions that have been provided in this study have been necessary.
\end{abstract}

\section{Introduction}

\section{Background of the study}

Transmedia storytelling, which was coined by Henry Jenkins, is described as a process where integral elements of a story are disseminated systematically across multiple channels in order to generate a uniform and synchronized entertainment experience [1]. In this regard, each of the media channels that are used in the dissemination process contributes uniquely to the unfolding story [1]. The multiple media through which a story may unfold include games, televisions, books and cinemas, among others [1]. According to Jenkins, the emergence of the concept of transmedia is underlined by five logics: the logic of entertainment, which, according to him, is evidenced by the presence of television schedules and reality shows in the American television; the logic of experts, which is embodied in the collective intelligence that is shared by fans in order to establish, create, produce and discuss issues; the logic of immersion, which motivates the participation of audiences; the logic of identification, which allows fans to create their identities, based on what they see or watch [2].

Jenkins has added that transmedia storytelling is a reflection of the economics of media amalgamation [3]. According to him, the contemporary media firms are horizontally integrated, implying that they have interests across a series of what used to be considered as distinctive media industries [3]. Thus, integrated media have advantages to disseminate their brands across numerous, distinct media platforms. According to researchers who have studied the concept, transmedia in its simplest form means "across media." Therefore, it is the flow of inform across two or more different media platforms.

The historical background of transmedia storytelling can be traced back to the Japanese marketing strategy known as media mix, which meant the strategic dispersal of contents across numerous representations [4]. The representations included gaming technologies, cellphones, broadcast media, and amusement parks, among others [4]. Once Jenkins came up with the concept, he defined seven core principles. The first principle is spreadability versus drillability, which is the ability and the level to which content can be shared and the influencing factors that make a person to share the content against the ability of a person to conduct an in-depth exploration of proper narrative extensions when they happen upon a fiction that truly captures their interests; the second principle is continuity versus multiplicity. In this case, some transmedia franchises encourage consistencies to achieve maximum credibility among all extensions; the third principle is immersion versus extractability; immersion entails the consumer entering into the world of information or story; with respect to extractability, the consumer is able to take the aspects of the story away with them as part of the resources that they disseminate in their everyday life; fourth principle is world-building, which is about the transmedia that provide a rich representation of the world in which stories flow; the fifth one is seriality [5]. Accordingly, Jenkins argues that transmedia storytelling has moved from serializing a narrative through a single medium in bits and has adopted the spreading of those bits of narratives across numerous media outlets [5]. The sixth principle is the subjectivity, which entails the exploration of the central narrative through new perceptions, including third parties [5]. This form of a diversity of views usually causes fans to be more interested in the kind of stories they choose to listen to or otherwise. Finally, there is the principle of performance. In this regard, the ability of transmedia extensions to result in information by consumers producing performances those are capable of being elements of the transmedia story itself [5].

What is important to note about the concept of transmedia storytelling is that it is generally used as a noun. When used as a noun, transmedia appears to be a wide concept, whose definition lacks specificity. It is too fluid to function properly with respect to its current definition and, it is clear, the concept it needs a new definition to enable it function properly, especially in the context of the digital world. Therefore, the focus of this study will be a critical analysis of the concept of transmedia as proposed by Henry Jenkins.

*Corresponding Author: Young-Sung Kwon, Department of Journalism and Mass Communication, Sungkyunkwan University, Jongno-gu, Seoul, KR 110-745 South Korea; E-mail: producerkwon@gmail.com

Citation: Byun H, Kwon YS (2016) A Systematization of the Concept of Transmedia: Update, Reinterpretation and Redefinition of the Concept. Int J Journalism Mass Comm 3: 120. doi: http://dx.doi.org/10.15344/2349$2635 / 2016 / 120$

Copyright: ( 2016 Byun et al. This is an open-access article distributed under the terms of the Creative Commons Attribution License, which permits unrestricted use, distribution, and reproduction in any medium, provided the original author and source are credited. 


\begin{abstract}
Problem statement
The problem with Jenkins' definition of transmedia in the form of a noun is that it does not reflect the reality as it is within the entire media industry. In Jenkins' definition of transmedia storytelling, elements of a fiction are dispersed methodically across several delivery channels in order to create a unified and coordinated entertainment experience. Importantly, Jenkins has argued that each integrated medium makes its own distinct contribution to the unfolding of a given story. Unfortunately, coordinating and collaborating with individual media conglomerate are a challenging undertaking [6]. Notably, within the integrated media industry, each media unit competes aggressively against other units, thereby limiting any chance for collaboration and coordination [7]. Further, even though entry points may tempt a range of consumers, they may also result in many points through consumers or audiences exit. For instance, if a text does not fit properly with others, people may be turned away, especially where movies are the subject matter [7]. Most importantly, with numerous creators of content, it is difficult to comprehend the whole dynamics of a particular transmedia franchise. Finally, it is not easy to create a world that is suitable for transmedia storytelling, based on its current definition, which makes it rigid; this means that it cannot be planned ahead as Jenkins suggests. The rigidity of the definition as a noun makes it difficult to create a world where transmedia storytelling can be undertaken successfully.
\end{abstract}

Therefore, while it is important to acknowledge that Jenkins' concept of transmedia is a milestone as far as the dispersal of information is concerned, there is a need to adjust and update the concept, and to redefine it in terms of a verb and not a noun. Doing these will make the concept of transmedia storytelling more realistic.

The purpose of this paper was to improve the concept of transmedia by adjusting, updating and redefining it in the form of verb.

\section{Justification and significance of the study}

This research study is justified on the ground that no other study has been done to provide a modification, an update and a new definition that looks at transmedia as a verb and not as a noun as espoused by Jenkins. With respect to significance, there are both practical and theoretical significance. The theoretical significance is that the study provided a modification, adjustment and a definition of the concept of transmedia that views it as verb, rather than a noun; the achievement of all these will make the concept to be more realistic than it is currently. Theoretically, the results of the study will contribute to the discourse on transmedia. It will reduce the research gap that exists with respect to the concept of transmedia. Importantly, the findings of the study will provide a foundation for further future studies on the same subject matter.

\section{Conceptual framework}

The study provided a new interpretation, a new definition and critical review of Jenkins' concept of transmedia storytelling. In this respect, the study achieved a new transmedia concept in the form of a verb, which will be easy to implement in different fields with respect to telling a story through various distinct media outlets.

\section{Literature Review}

\section{Media convergence and transmedia storytelling}

Transmedia storytelling is a concept that emerged around 2003 through the works of Henry Jenkins. However, Baarspul [6] traces the origin of the concept to the book Playing with Power in Movies, Television and Video Games in 1991, the work of Marsha Kinder, who had discussed issues of "transmedia intertextuality." Nonetheless, according to Jenkins, as quoted by Long [8] and Breum and Midtgaard [9], transmedia storytelling involves the use of different media outlets to tell a single story. Long [10] has explained that, during transmedia storytelling, for instance, the first chapter of a story may be told through a television show, the second one may be through a film, while the third may be through a video game. A perfect example that Jenkins has given as to transmedia storytelling is the Matrix, a story that has been told through various media outlets, such as video games and a sequence of short anime films. The other example is the Blair Witch, which is a story that has been told in the same way as the Matrix. However, Kim and Hong [11] have observed that there are certain similarities between transmedia and One-Source Multi-User strategies (OSMU). In this respect, it can be argued that, for instance, the Matrix, can be explained by both transmedia and OSMU, raising a question of how unique transmedia storytelling is from other strategies like OSMU. Fair enough, it can further be argued that other strategies can achieve what can be achieved through transmedia storytelling.

Notably, since its inception, the concept of transmedia has been applied in various contexts. For instance, Hayati [12] has discussed its application in education and creative contexts. Hayati [12] has argued that, using transmedia, children can start learning through any accessible media. Hayati [12] further opines that, when the media interlinked, children become motivated to explore even more media sources of learning. Evidently, the process of transmedia story telling, as told by the researcher, is facilitated by the presence of technology, especially the web 2.0 .

In addition to the views of Hayati [12], Vukadin [13] has noted that, apart from education studies, the concept of transmedia has been studied from the perspective of culture, marketing, and semiotics, the contexts of which involves interactivity and participation of both producers and consumers, which are crucial elements of transmedia, as explained by Bourdaa [14]. In relation to this, Edwards [15] has explained that transmedia storytelling is as significant evidence of the merging competing trends, which is a representation of corporate synergies and the opportunity for audiences to participate in the content production process. However, Vukadin [13] and Baarspul [6] have observed that, despite the importance of transmedia in various fields, it remains vaguely defined. The argument of Baarspul [6] tends to add on Vudkadin's [13] position by advancing the idea that there are inconsistencies between Jenkins' definition and the way it is implemented. According to Baarspul [6], Jenkins' definition raises a question as to the extent to which transmedia storytelling unfolds across various media platforms. The problem of the definition of the concept of transmedia storytelling has been discussed in a subsequent subsection.

The prevalence of transmedia storytelling has been facilitated by the development of the digital media, which has created many media platforms through which a story may unfold. In this regard, Merkin [16] has contended that as the digital and media convergence unfolds and media outlets works hard to continue being going concerns within the entertainment industry, transmedia experiences are increasingly becoming common. In this regard, Merkin [16] has argued that the advent of transmedia and the digital convergence has made it 
possible for the coordination of games, videos, and films. According to , the ability to create transmedia, especially in the context of digital technology, results in a deeper level of experience for consumers, who are also considered co-producers. While commenting about the interaction between transmedia and technology, Kim and Hong [11] has explained the possibility of transmedia production and storytelling has been facilitated by the proliferation of computers, which has enabled digital production of media content.

\section{The interpretation of transmedia storytelling}

Many publications have been made with respect to the concept of transmedia storytelling. Ciancia [17] has argued that transmedia is a cultural standard that enables audiences to participate in making or assigning meanings of narrative processes in the world. However, Ciancia [17] has noted that, despite the importance of transmedia in storytelling, there are concerns as to the real meaning of the concept. In this respect, Gambarato [18] has stressed that there is no agreeable meaning or description of what transmedia storytelling could be. In this regard, the author is of the opinion that, despite the openness of the definition of the concept of transmedia storytelling, it is possible to trace its specific characteristics. According to him, the concept of transmedia is a combination of "trans" and "media", whereby he defines "trans" as having the meaning of "beyond", "traverse", "through", and the dissemination of the ideas of wholeness. Hence, the author concludes that transmedia means the passage of a story through a diversity of media. While quoting Geoffrey Long, Gambarato [18] has suggested that the concept of transmedia should not be viewed as a noun, but as an adjective.

The confusion as to the strict definition of transmedia storytelling has been aggravated by the discussions of other scholars. For instance, Christy Dena, as quoted by [19], has challenged the elements of Jenkins' definition of transmedia storytelling. In this case, Dena has used the concepts of "transfiction" and "cross-media entertainment" in lieu of Jenkins' transmedia storytelling. While talking about transfiction, Dena has referred to stories that are disseminated through more than one medium, including texts, video games and films; the story is significantly dependent on all elements that are one each medium or device. Although Dena has explained that, unlike Jenkins' concept where the transmedia extensions are individually independent, the media through which a story unfolds are dependent on each other. Even though Jenkins and Dena appear to have referred to the same thing, in Jenkins' transmedia storytelling, the media components are independent and an audience can enjoy a story without necessarily having access to another medium. On the contrary, the stand with respect to Dena's transfiction is that the media are not dependent Evidently, Jenkins and Dena's definitions refer to the same thing, only that Dena's one is stricter than that of Jenkins.

While contributing to the discourse, Scolari [21] has contended that the concept of transmedia storytelling still requires a lot of research. In this respect, Scolari [21] is of the opinion that the definition of transmedia storytelling is still not clear and, hence, requires further refining to establish the limits and possibilities.

\section{Research gap}

Even though the concept of transmedia storytelling is gaining currency in various fields, it clear from various literature that it is a concept that is still devoid of specific definition, a scenario that makes it difficult to implement and to distinguish it from other strategies such as OSMU. Importantly, it is evident that many scholars still feel that there is need for further studies in order to update and redefine the concept of transmedia, because the current definition is in the form of a noun, which makes it difficult to implement. Hence, there is a need to redefine it as a verb, yet no studies exist as this need.

\section{Research Method}

\section{Sources and method of data collection}

The study was focused on a critical analysis of Jenkins' transmedia storytelling concept. In this case, the study involved critical analysis of different materials that have been produced with respect to transmedia storytelling. Therefore, data was collected through secondary methods, from journals and research reports in the college library and online academic databases. The most important inclusion criterion was that the materials included were about the definition of transmedia storytelling in different variants, because this study was about the need to modify, update and redefine the concept in terms of a verb. The preference for secondary qualitative sources of data is because less time is required to obtain data and that there is no need to interact with a population during a study.

\section{Methods of data analysis}

A historical analysis technique was used to analyze the materials that were obtained from various sources. A historical analysis is very significant in terms of analyzing the history of a phenomenon. In this regard, the analysis process helps in the identification of gaps, which enables a researcher to come up with a solution. In the case of this research study, a historical analysis was focused on how transmedia has been defined overtime, since Jenkins coined it in 2003. The analysis was also focused on how it has been difficult to implement transmedia storytelling due to its definition in terms of a noun. From the analysis, the researcher suggested how the concept of transmedia can best be updated and redefined in order to make its implementation more practical in the real life situation. The results of the study were presented narratively.

\section{Analysis and Discussions}

\section{Critical analysis of Jenkins' conception of transmedia}

According to Henry Jenkins, transmedia story telling is about telling a story across a multiplicity of media, with each medium making a unique contribution to the unfolding of the story [7]. The implication of this conception is that each medium that has been involved in the unfolding of a story tells a different part of the story, with each of the parts systematically synchronizing with each other, thereby making a complete story. However, the problem arises with respect to a number of factors, one of which is the involvement of the target audiences with the media. When a story unfolds through transmedia, every audience must be able to get the whole story in order to understand its end. However, not all target audiences may be interested in every media through which parts of a story systematically unfolds. For instance, Henry Jenkins has given an example of the Matrix as representing a transmedia storytelling [7]. The story has been told through video games, live action films and a collection of comic books. In this regard, an audience may be interested in only the comic books and the live action films, but not in the games. Consequently, it means that the audience will not be able to get or understand the part of the story that has been dispersed through video games. The matrix represents only a few areas on which the concept of transmedia is problematic. 
Another area in which the concept of transmedia has become problematic is with respect to the age and literacy of the audiences. Evidently, Jenkins' definition seems to be insensitive to the fact that, in order to take advantage of transmedia storytelling, consumers require advanced literacy about the media. Further, consumers involved in the context of transmedia require appropriate moral, cognitive an emotional development. Unfortunately, even though Jenkins does not define the appropriate demographics of consumers who are involved in the transmedia storytelling, it is a fact that children do not possess the foregoing qualities, which are essential, if they are to participate in transmedia storytelling. Evidently, this problem arises mainly because of Jenkins' definition of the concept as a noun, which leaves no room for flexibility when deciding to tell a story through different media. Importantly, providing a definition that is not in the noun form enables the application of the concept in the context of children or individuals who are not possessed of the media literacies and skills, which are essential with respect to taking advantage of the concept.

Moreover, evidence shows that transmedia storytelling relies on a fan base; this means that the larger the fan based, the more successful transmedia storytelling becomes. The converse is true. The growth of the fan base can only be facilitated when fans have transmedia literacy and skills that are necessary for them to interact effectively and beneficially with different media carrying different components of a story. The problem arises when many of the target audience are not interested in interacting other media containing other components of a story. If that happens, then such audiences may not achieve a complete story as intended by storytellers.

\section{Re-interpretation of transmedia storytelling}

It is evident that Henry Jenkins' transmedia storytelling is among the most captivating phenomena resulting from the modern media contexts. Despite it being an important concept that has emerged in the media and communication industry, there are already certain problems that are associated with it, especially with respect to its implementation as a concept. The problem results from, partly, the fact that it is an emerging concept within the area of media and there is no consensus on its definite meaning. Even so, the current definition, as provided by Henry Jenkins, has been popularly adopted by those who have attempted to give it a meaning. Jenkins' definition has taken the form of a noun, which underlies the problem with it. In this respect, it is not yet clear what Jenkins sought to mean by his definition, which has remained largely vague.

The vagueness of the definition of transmedia storytelling can best be captured when it is compared with One-Source Multiple-Use (OSMU) concept [20]. Transmedia storytelling is significantly similar to OSMU in the sense that they can both be used to explain the same thing [20]. For instance, Jenkins has provided the Blair Witch and the Matrix as examples of transmedia storytelling. However, the dissemination of the stories in the movies can still be dispersed by thorough the One-Source Multiple User strategy. The implication of this position is that transmedia storytelling is unique to distinguish it from other concepts and this is the reason there was a need to reinterpret it. However, in contrast to transmedia storytelling, a story flows form a single source to may audiences. To such an extent, it is not easy to interpret transmedia storytelling differently from OSMU. Even so, the difference is that, with OSMU, the entire story reaches many audiences through a single medium or a single medium carries all the components of a given story. On the contrary, with respect to transmedia storytelling, a story does not flow to an audience through a single source. Instead, distinct components flow to an audience through different media platforms. In this regard, in order to make the distinction, a re-interpretation from the perspective of the audience or consumer is necessary and appropriate, because the current interpretation tends to emphasize the source of a story and the manner in which its components reach the target audience or consumers. Considering the perspective of the consumer, transmedia storytelling becomes an action in which the consumer contributes to the realization of a full, coherent story. Hence, this research study suggests that there should be developed an interpretation of transmedia storytelling that focuses on the perspective of audiences.

In the contexts of his definition, while it is possible to be attempted to think of storytelling as a way of creating a story through multimedia channels, it is more apparent that it connotes a narrative as constructed by audiences as they interact with different media telling the story. In this regard, it is the audiences who actually ultimately collect the components of elements of a story from different media channels to make one whole narrative. Hence, viewed from the perspective of a storyteller, the concept takes the form of a noun and it implies that the story is created and dispersed through multimedia without regard to whether the audience will finally get the whole story. Getting the whole story may not be guaranteed. For instance, Henry Jenkins has argue that there is still a lot of information that not yet known with respect to what is likely to motivate an audience seek out other bits of information or components of an unfolding story. Conversely, from the perspective of the audience, the concept of transmedia storytelling is representative of a verb, tending to imply that an audience gathers components of a story from different media platforms in order to construct one whole narrative before consuming it.

Even though it is possible for an audience to construct the whole story from different media channels, it is only possible for audience who are fans and enthusiastic about all media through which a story they may seek are dispersed; an audience, who may not be aware of the medium through which a component has been dispersed or who may not be interested in it, may cannot understand a whole story. Nonetheless, Jenkins has argued that the narrative as a whole is predetermined, meaning that a story is never planned ahead, a fact that makes transmedia storytelling a not so useful concept when it comes to dispersing stories with respect to the future, because the whole story is not instantly there for an audience. The audience must join the components from different media by himself. Apparently, the story is never their when the audience finally start interacting with the media channels carrying its components; the components must be joined together in order to make a meaning. In this case, the audience must be skilled and knowledgeable enough to ensure that the components are coherently synchronized. Thus, there was a need to re-interpret and redefine the concept of transmedia as used with the storytelling.

\section{A Re-definition of transmedia storytelling}

At this point, it is important to analyze the meaning of "transmedia." The term is composed of two components: the first one is the "trans" and the second one is the "media." "Trans" means "through", "across" or "beyond" and the "media" are the channels through which information flow variously from sources to target audiences. Therefore, "transmedia" means "across" or "beyond" many channels. The term can be associated with any of the following: entertainment, games, arts, storytelling and branding, among others. 
The concept of transmedia, as it stands, cannot be used in isolation. It must be used in conjunction with another word or phrase in order to make a meaning. In the case of Jenkins, the term has been used with "storytelling," which is, strictly, in a gerund form. In the English language, a gerund is a noun resulting from a verb after the addition of "ing" at the end. It is important to note that a gerund is an example of nonfinite verb. Therefore, storytelling is a nonfinite verb; a verb is a doing word, meaning that it is a word that connotes an action, and not a thing per se. In the context of transmedia, storytelling is supposed to be considered as a verb, so that the person or people telling a story are referred to as storytellers; storytellers tell a story and the action of telling any story is referred to as storytelling. Accordingly, storytelling is about expressing emotions, thoughts and problems through such media as writings, explanations, arts and songs, among others.

Therefore, having identified "storytelling" as being in a nonfinite verb form, the concept of transmedia storytelling can be redefined to mean the process in which a storyteller tell a story across different media platforms. Given this new definition, the question arises as to the role of "transmedia" appearing before "storytelling." In this case, the role of "transmedia" is to signal the way the storytelling process takes place, through different channels. Nonetheless, "transmedia" can be disintegrated into two components: "trans" and "media." Ideally, "trans" is a prefix with specific meanings, some of which include words such as "beyond", "across" and "transverse." Importantly, "media" has its meaning in the context of communication platforms. Linguistically, it is a plural form of medium, which implies a channel. Hence, the concept of transmedia has the connotation of between communication platforms, or from one communication channel to another.

This definition is slightly at variant with Jenkins' conception of transmedia storytelling. In his definition, Jenkins views "transmedia storytelling" as representative of a process in which integral elements of a fictional story are disseminated systematically through a multiplicity of delivery channels. The problem with Jenkins' definition is that he considers transmedia storytelling as a representation and not as the performance of an act. Importantly, his definition of transmedia as a noun sounds too broad, because, rather than being a definition communicating a concept, it tends to make the concept of "transmedia storytelling" clearly undefined.

Given the foregoing analysis, the new interpretation of the concept of transmedia storytelling is as follows: the act of disseminating or dispersing integral elements of a story systematically across multiple delivery channels with a view to generating a synchronized and coordinated entertainment experience. Put differently, the concept refers to designing of a story to unfold across or through multiple media channels in an expansive way, rather than being repetitive in different media channels.

This definition does not fundamentally vary from that of Jenkins, only that it turns it into an act or the doing of something rather than a representation of it. If transmedia storytelling is defined as an act of telling a story, it opens itself as a concept involving the collaboration between two or more individuals, including the target consumers who are considered as co-creators of stories.

\section{Conclusion and Recommendations}

\section{Conclusion}

Int J Journalism Mass Comm

ISSN: 2349-2635
This study sought to achieve a number of objectives. The first objective was to provide a new interpretation of transmedia, to suggest an adjustment and a new definition of transmedia as a verb, and to provide a critical analysis of Jenkins' conception of transmedia storytelling. In achieving the objectives, the study sought to use qualitative research methods.

With respect to suggesting a new interpretation, this study and managed to provide a new interpretation, which focuses on the perspective of the audience of the consumer. In this regard, the problem with the interpretation of transmedia storytelling as provided by the arguments of Henry Jenkins was viewed as general and vague in nature. This was because Jenkins talked of a fictional story being dispersed over different media platforms. With such a description, Jenkins failed to discuss or specify the specific roles of a storyteller and the audience or consumer; this is one of the most important reasons there was a need to suggest a new interpretation of the concept of transmedia storytelling, which should focus on the perspective of the consumer also, not just the storyteller. In this regard, it is concluded that transmedia storytelling involves story tellers coming up with different components of a story and dispersing them through different media platforms, while the audience or consumer plays the role of seeking those components from various media platforms and synchronizing them to form a coherent single story.

With the second objective, it is worth pointing out that the study has come up with an adjusted, new definition of transmedia storytelling. The need to redefine the transmedia storytelling was because Jenkins' definition was in the form of a noun, the definition of which made it vague in terms of meaning an implementation. Even Jenkins had acknowledged that the concept was still a growing area within the media industry and, hence, was understood differently by different authors. In this respect, the development of the concept was not taking shape in the manner in which it would, only if it had a different definition. Therefore, while Jenkins' definition was in the form of a noun, this study has suggested that it should be defined in the form of a verb. Accordingly, the new definition that has been suggested in this study is: the process in which storytellers tell a story across different media platforms. Considering this definition, it is important to note that Jenkins' definition of the concept was strictly a noun. With respect to the final objective, the study has revealed that Jenkins' conception of transmedia storytelling has been vague, especially with regard to the examples of Blair Witch and Matrix, the movies of which, even though have been told through different media channels, can also be explained through OSMU. The study has pointed out the weaknesses of Jenkins' ideas on transmedia storytelling, which have been used to show that the suggestions that have been provided in this study have been necessary.

\section{Recommendation}

Based on the outcomes of this study, a number of recommendations are necessary. First, the concept of transmedia storytelling is still nascent and growing. In this respect, it is recommended that further studies should be done about the concept, especially with respect to providing reasons why it should be defined as a verb. It is further recommended that future studies should use the current results as a foundation for further research studies; this will help in refining and making specific the definition of transmedia storytelling. Second, given that this study has provided new suggestions as to the interpretation and definition of transmedia storytelling, it is recommended that they should be adopted as an addition to the development of the concept. 
Citation: Byun H, Kwon YS (2016) A Systematization of the Concept of Transmedia: Update, Reinterpretation and Redefinition of the Concept. Int J Journalism Mass Comm 3: 120. doi: http://dx.doi.org/10.15344/2349-2635/2016/120

Page 6 of 6

It is believed that the new interpretation and definition are more specific than Jenkins' and that it will be easier to work with the concept than it was before.

Third and finally, with respect to research methodology, it is recommended that a primary research study should be done in the future. It is important to note that this study utilized secondary data. Primary data often reflect the most current information regarding a subject of study. Importantly, it is specifically recommended that future studies on a similar subject matter should conduct focus group discussions so that rich information can further be generated in furtherance of the study of transmedia storytelling. Further, the analysis process of collected data should be done differently in the future. For instance, thematic analyses can be used.

\section{Competing Interests}

The authors have no conflict of interest to disclose.

\section{Funding}

This paper was supported by Sungkyun Research Fund, Sungkyunkwan University, 2014.

\section{References}

1. Baarsopul MP (2012) Where transmedia storytelling goes wrong: A preliminary exploration of the issues with transmedia storytelling (Bachelors thesis). Utrecht University, Utrecht.

2. Bourdaa M (2013) 'Following the pattern': The creation of an encyclopedic universe with transmedia storytelling. Adaptation 6: 202-214.

3. Breum AC, Midtgaard HS (2013) Story bridges in transmedia (Master's thesis). Aalborg University, Demark.

4. Ciancia M (2013) What is transmedia? Projects and thoughts beyond the buzzword in Cleland K, Fisher L, Harley R (Eds) Proceedings of the $19^{\text {th }}$ International Symposium of Electronic Art, ISEA, Sydney.

5. Edwards LH (2012) Transmedia storytelling, corporate synergy, and audience expression. Global Media Journal 12: 1-10.

6. Gambarato RR (2013) Transmedia project design: Theoretical and analytical considerations. Baltic Screen Media Review 1: 80-100.

7. Godfrey A (2005) The Ever-changing View: A History of the National Forests in California, 1891-1987. California, CA: USDA Forest Service, California.

8. Harvey C (2015) Fantastic transmedia: Narrative, play and memory across science fiction and fantasy story worlds. London, UK: Palgrave Macmillan.

9. Hayati D (2012) Transmedia storytelling: A study of the necessity, features and advantages. International Journal of Information and Education Technology 2: 196-199.

10. Jenkin $\mathrm{H}$ (2003) Transmedia storytelling

11. Jenkins $\mathrm{H}$ (2006) Convergence Culture: Where Old and New Media Collide. New York, NY: NYU Press.

12. Kalogeras S (2014) Transmedia storytelling and the new era of media convergence in higher education. Charlotte, USA: Palgrave Macmillan.

13. Kim J, Hong J (2013) Analysis of Trans-media Storytelling Strategies. International Journal of Multimedia and Ubiquitous Engineering 8: 1-9.

14. Long GA(2000) Transmedia storytelling business, aesthetics and production at the Jim Henson Company (Masters dissertation). Massachusetts Institute of technology, Massachusetts.

15. Lunning $F(2010)$ Frenchy Lunning is professor of liberal arts at the Minneapolis College of Art and Design. Minneapolis, MN: $U$ of Minnesota Press.

16. Merkin AD (2003) The management of transmedia production in an era of media and digital convergence (Master's dissertation), Massachusetts Institute of Technology, Massachusetts.

Int J Journalism Mass Comm

ISSN: 2349-2635
17. Scolari CA (2009) Transmedia storytelling: Implicit consumers, narrative worlds, and branding in contemporary media production. Int $\mathrm{J}$ Communication 3: 586-606.

18. Transmedia Lab. (n.d). Henry Jenkins explains his vision of transmedia and audience engagement.

19. Veglis A (2012) From Cross Media to Transmedia Reporting in Newspaper Articles. Pub Res 28: 313-324.

20. Vukadin A (2014) Bits and Pieces of Information: Bibliographic Modeling of Transmedia. Cataloging \& Classification Quarterly 52: 285-302. 